Article

\title{
Energy Metabolism in the Failing Right Ventricle: Limitations of Oxygen Delivery and the Creatine Kinase System
}

\author{
Ewan D. Fowler ${ }^{1,2, * \mathbb{C}}$, David Hauton ${ }^{1,3}$, John Boyle ${ }^{1}$, Stuart Egginton ${ }^{1}\left(\mathbb{D}\right.$, Derek S. Steele ${ }^{1}$ and \\ Ed White ${ }^{1}$ \\ 1 Multidisciplinary Cardiovascular Research Centre, University of Leeds, Leeds LS2 9JT, UK; \\ david.hauton@chem.ox.ac.uk (D.H.); medjpb15@gmail.com (J.B.); s.egginton@leeds.ac.uk (S.E.); \\ D.Steele@leeds.ac.uk (D.S.S.); E.White@leeds.ac.uk (E.W.) \\ 2 Cardiac Research Laboratories, School of Physiology, Pharmacology and Neuroscience, University of Bristol, \\ Bristol BS8 1TD, UK \\ 3 Metabolomics Research Group, Chemistry Research Laboratory, University of Oxford, Oxford OX1 3TA, UK \\ * Correspondence: ewan.fowler@bristol.ac.uk
}

Received: 27 March 2019; Accepted: 10 April 2019; Published: 12 April 2019

check for updates

\begin{abstract}
Pulmonary arterial hypertension (PAH) results in hypertrophic remodeling of the right ventricle (RV) to overcome increased pulmonary pressure. This increases the $\mathrm{O}_{2}$ consumption of the myocardium, and without a concomitant increase in energy generation, a mismatch with demand may occur. Eventually, RV function can no longer be sustained, and RV failure occurs. Beta-adrenergic blockers (BB) are thought to improve survival in left heart failure, in part by reducing energy expenditure and hypertrophy, however they are not currently a therapy for PAH. The monocrotaline (MCT) rat model of PAH was used to investigate the consequence of RV failure on myocardial oxygenation and mitochondrial function. A second group of MCT rats was treated daily with the beta-1 blocker metoprolol (MCT + BB). Histology confirmed reduced capillary density and increased capillary supply area without indications of capillary rarefaction in MCT rats. A computer model of $\mathrm{O}_{2}$ flux was applied to the experimentally recorded capillary locations and predicted a reduction in mean tissue $\mathrm{P}_{\mathrm{O} 2}$ in MCT rats. The fraction of hypoxic tissue (defined as $\mathrm{P}_{\mathrm{O} 2}<0.5 \mathrm{mmHg}$ ) was reduced following beta-1 blocker (BB) treatment. The functionality of the creatine kinase (CK) energy shuttle was measured in permeabilized RV myocytes by sequential ADP titrations in the presence and absence of creatine. Creatine significantly decreased the $\mathrm{K}_{\mathrm{mADP}}$ in cells from saline-injected control $(\mathrm{CON})$ rats, but not MCT rats. The difference in $\mathrm{K}_{\mathrm{mADP}}$ with or without creatine was not different in $\mathrm{MCT}+\mathrm{BB}$ cells compared to CON or MCT cells. Improved myocardial energetics could contribute to improved survival of $\mathrm{PAH}$ with chronic BB treatment.
\end{abstract}

Keywords: myocardial hypoxia; creatine kinase; pulmonary artery hypertension; beta blocker; monocrotaline; right ventricle failure; heart failure

\section{Introduction}

Pulmonary arterial hypertension (PAH) arises when the vascular resistance in the normally low pressure, high compliance pulmonary circulation increases due to muscularization or occlusion of pulmonary arterioles [1,2]. The increased load on the right ventricle (RV) causes adaptive remodeling, such as hypertrophy of RV myocytes, increased heart rate, and increased reliance on inotropic beta-adrenergic signaling pathways [3]. These changes initially preserve cardiac output at the cost of increased heart rate and energy expenditure [4,5]. Chronic elevated beta-adrenergic signaling reduces 
beta-adrenoceptor expression, which compromises contractile reserve [6-8]. Eventually the RV is unable to meet demands and RV failure results [9].

It is believed that problems in energy supply could lead the heart to become "energy starved", due to its continual high rate of ATP turnover [10]. In human heart failure, lower levels of high-energy phosphates like ATP and phosphocreatine (PCr) are associated with worse outcomes [11]. The causes of this are unknown; however, there is evidence of myocardial hypoxia in PAH, as well as left heart failure shown by increased expression of hypoxia-inducible factor-1 (HIF-1) and vascular endothelial growth factors (VEGFs) [12-16]. This may drive a shift in substrate utilization from fatty acid oxidation to glycolysis in both animal and human PAH $[17,18]$.

Myocardial hypoxia in PAH could be explained by reduced right coronary artery flow in proportion to increased RV mass and increased heart rate, which decreases coronary perfusion time [5,19]. Increased myocyte diameter is also predicted to reduce tissue oxygenation, due to increased diffusion distance from capillaries [20]. In human PAH, capillary density was reduced in the failing RV with a reduction in pro-angiogenic miR-126 expression, whereas injection of miR-126 in a rodent model of PAH increased capillary density and cardiac output [21]. Depending on the stage of disease, there may also be increased expression of VEGF inhibitors and decreased expression of angiopoetin- 1 and apelin proteins involved in capillary maintenance [22]. Hypoxia will reduce mitochondrial ATP synthesis and limit the cell's ability to perform work; therefore, reducing myocardial hypoxia could be a therapeutic target for PAH.

To work efficiently, ATPases like sarco/endoplasmic reticulum $\mathrm{Ca}^{2+}$ ATPase (SERCA) and myosin ATPase require a high free energy of ATP hydrolysis, achieved by a large ratio of ATP $(\sim 5 \mathrm{mM})$ to ADP $(<50 \mu \mathrm{M})$. This is maintained in the vicinity of ATPases by cytosolic creatine kinase (CK), which reversibly catalyzes the transfer of high-energy phosphate from phosphocreatine ( $\mathrm{PCr}$ ) to ADP, producing ATP and creatine $(\mathrm{Cr})$. CK located in the mitochondrial intermembrane space (CK-mt) generates PCr and promotes ATP synthesis by maintaining a high mitochondrial [ADP] [23,24]. This shuttling of energy from mitochondria to cellular compartments using the CK system becomes particularly important for cell survival during hypoxia and with moderately increased $\mathrm{O}_{2}$ flux [25]. However, expression of CK isoforms is reduced in PAH and left heart failure, which is associated with impaired myofilament function and reduced coupling to respiration [26-29]. This raises the prospect that improving CK function may benefit a failing RV, and therapies which do so should be investigated.

Beta-adrenergic receptor blockers (BB) are not currently recommended as a treatment for PAH; however, recent clinical [30-33] and preclinical evidence suggests they may be safe or beneficial [34-38]. We recently established a BB treatment regime in a monocrotaline (MCT) rat model of PAH, and it slowed the progression to heart failure [37]. Notably, BB ameliorated MCT RV myocyte hypertrophy and showed trends towards improved expression of CK isoforms. Our aim for this study was to investigate whether RV hypoxia and CK-mediated mitochondrial respiration were improved in MCT rats following chronic BB treatment.

\section{Results}

PAH was initiated by a single intraperitoneal injection of monocrotaline into male Wistar rats $(200 \pm 20 \mathrm{~g})$. We employed a three-group study design, consistent with previous publications [34-38]. MCT-injected rats were treated daily with either the beta-1-selective blocker metoprolol $(10 \mathrm{mg} / \mathrm{kg}$; $\mathrm{MCT}+\mathrm{BB}$ group) or with a vehicle (sucrose solution; MCT group) beginning on day 15 post-MCT injection [37]. Saline injected control rats (CON group) were treated with the vehicle. MCT rats were killed when showing symptoms of heart failure [37]. MCT $+\mathrm{BB}$ and $\mathrm{CON}$ rats were killed on the median survival day of MCT rats ( $23 \pm 1$ days) as time-matched treatment groups. Frozen tissue for histology and myocytes were isolated from the same cohort of animals used in [37], which also contains detailed in vivo characterization of the BB treatment model.

The heart weight to body weight ratio was greater in MCT rats than CON rats, mainly due to increased RV weight (Table 1). The heart and RV weight of MCT + BB rats was significantly less than 
MCT rats, consistent with a reduction in RV myocyte hypertrophy [37]. Lung weight was greater in $\mathrm{MCT}$ and $\mathrm{MCT}+\mathrm{BB}$ rats than $\mathrm{CON}$, possibly indicative of pulmonary edema arising from increased pulmonary artery systolic pressure.

Table 1. Body and organ characteristics of control (CON), monocrotaline (MCT), and beta-1-selective blocker metoprolol (MCT + BB) groups.

\begin{tabular}{cccc}
\hline & CON & MCT & MCT+BB \\
\hline Body weight $(\mathrm{g})$ & $330 \pm 7$ & $294 \pm 13$ & $273 \pm 10^{* *}$ \\
HW:BW $(\mathrm{mg} / \mathrm{g})$ & $3.90 \pm 0.13$ & $6.22 \pm 0.34^{* * *}$ & $5.07 \pm 0.34^{*, \dagger}$ \\
RV:BW $(\mathrm{mg} / \mathrm{g})$ & $0.75 \pm 0.05$ & $1.42 \pm 0.12^{* * *}$ & $0.90 \pm 0.07^{\dagger+}$ \\
LV + S:BW (mg/g) & $2.78 \pm 0.17$ & $3.00 \pm 0.19$ & $2.96 \pm 0.09$ \\
Lung:BW (mg/g) & $7.53 \pm 0.82$ & $10.3 \pm 0.3^{*}$ & $10.2 \pm 0.6^{*}$ \\
Liver:BW (mg/g) & $39.6 \pm 1.3$ & $40.6 \pm 2.8$ & $49.2 \pm 1.8^{*,+}$ \\
\hline
\end{tabular}

HW: heart weight; BW: body weight; RV: right ventricle, LV + S: left ventricle + septum. ${ }^{*} p<0.05,{ }^{* *} p<0.01,{ }^{* * *} p<$ 0.001 vs. CON ${ }^{+} p<0.05,{ }^{++} p<0.01$ vs. MCT. $n=7 \mathrm{CON}, 5 \mathrm{MCT}, 5 \mathrm{MCT}+\mathrm{BB}$ rats per group.

Histology was conducted on cryosections of RV myocardium from CON, MCT, and MCT+BB rats. $10 \mu \mathrm{m}$ thick sections were stained with fluorescein-conjugated lectin to label the capillary network and muscle fiber boundaries (Figure 1A). Capillary locations were digitized, and the capillary supply area, in which all points were closer to a central capillary than to any other capillary, was computed using Voronoi tessellation (Figure 1B). Capillary density was reduced by $45 \%$ in MCT and by $33 \%$ in MCT + BB compared to CON $(p<0.001)$, but was increased in MCT + BB compared to MCT $(p<0.05)$ (Figure 1C). This could indicate capillary rarefaction or be a consequence of angiogenesis failing to match RV myocyte hypertrophy [37]. The ratio of capillaries to muscle fibers was not different between groups (Figure 1D). The mean capillary supply area was increased by $81 \%$ in MCT $(p<0.001)$ and by $53 \%$ in $\mathrm{MCT}+\mathrm{BB}(p<0.01)$ compared to $\mathrm{CON}$, but was reduced by $16 \%$ in MCT+BB compared to MCT $(p<0.05)$ (Figure 1E). This indicates that angiogenesis did not match muscle fiber hypertrophy in MCT, but that BB ameliorated the increase in the capillary supply area.

To investigate whether perfusion mismatch could lead to tissue hypoxia, a finite element model of $\mathrm{O}_{2}$ diffusion and consumption in the myocardium was fitted to the experimentally determined capillary locations $[39,40]$. The model was implemented in Matlab, and is available with a user-friendly graphical user interface [41]. Figure 2A shows exemplary heatmaps of tissue $\mathrm{P}_{\mathrm{O} 2}$ surrounding the capillaries (indicated by white circles). It is apparent that a greater proportion of MCT tissue is predicted to be at low $\mathrm{P}_{\mathrm{O} 2}$ compared to $\mathrm{CON}$ tissue. The mean tissue $\mathrm{P}_{\mathrm{O} 2}$ in MCT was $73 \%$ less and in $\mathrm{MCT}+\mathrm{BB}$ was $61 \%$ less than that found in $\mathrm{CON}(p<0.05)$ (Figure 2B). Mean tissue $\mathrm{P}_{\mathrm{O} 2}$ was not significantly different in MCT compared to MCT+BB $(p=0.06)$. When tissue $\mathrm{P}_{\mathrm{O} 2}$ is greater than $\sim 0.5 \mathrm{mmHg}$, the tissue $\mathrm{O}_{2}$ flux is approximately constant, whereas below this critical level $\mathrm{O}_{2}$ utilization falls sharply [42]. Using this criterion for hypoxia, the percentage of hypoxic tissue was significantly increased in MCT compared to $\mathrm{CON}(p<0.05)$. The hypoxic area was also greater in MCT+BB compared to CON; however, the area was reduced compared to MCT alone $(p<0.05)$ (Figure 2C).

We investigated whether differences in $\mathrm{O}_{2}$ extraction could influence the model results. Proliferation of interstitial fibrosis could act as a barrier to $\mathrm{O}_{2}$ diffusion from the capillaries to muscle fibers $[43,44]$, however we found no difference between groups in the extent of fibrosis assessed by picrosirius red staining (CON: $3.2 \pm 0.4 \%$; MCT: $2.5 \pm 0.3 \%$; MCT+BB: $2.7 \pm 0.4 \% ; p=0.44$ ). A reduction in mitochondrial mass could reduce tissue $\mathrm{O}_{2}$ utilization and ameliorate hypoxia [45]. Citrate synthase activity (a marker of mitochondrial mass [46]) was measured in RV homogenates taken from the same hearts used for histology. Citrate synthase activity did not differ between groups (CON: $5.39 \pm 0.45 \mathrm{IU} / \mathrm{mg}$; MCT: $4.37 \pm 0.47 \mathrm{IU} / \mathrm{mg} ; \mathrm{MCT}+\mathrm{BB}: 4.30 \pm 0.42 \mathrm{IU} / \mathrm{mg} ; p=0.19$ ), indicating no change in overall mitochondrial density. These data indicate that tissue hypoxia, which is ameliorated by chronic BB treatment, may be a limiting factor in the RV of MCT rats. 
A
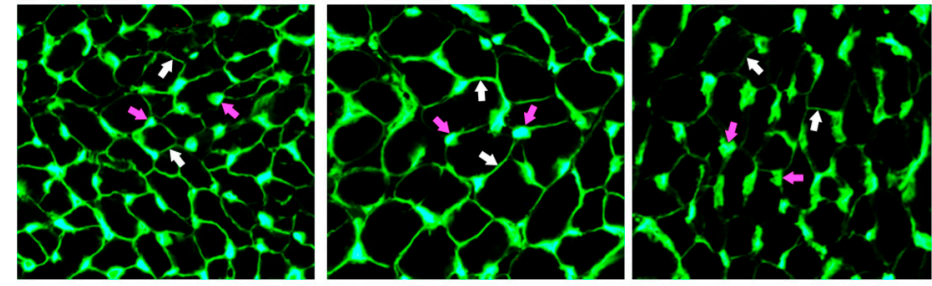

B

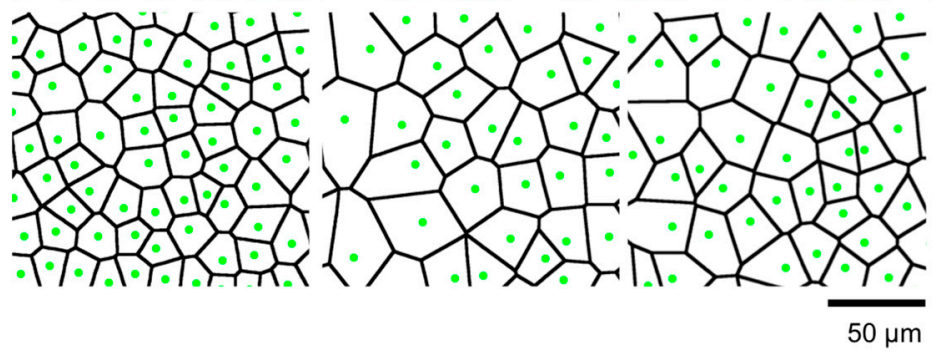

C

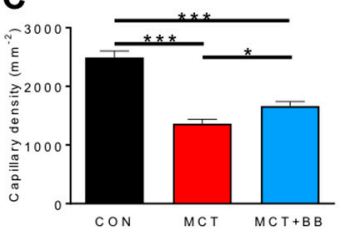

D

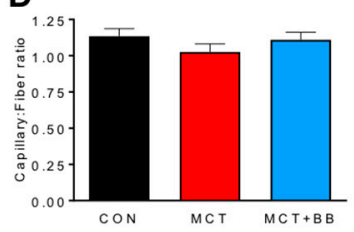

E

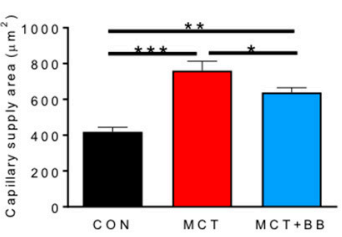

Figure 1. Capillary density is decreased and capillary supply area in the right ventricle (RV) is increased by MCT treatment. (A) Exemplar images showing intense fluorescent labelling of capillaries (magenta arrows) and less intense labelling of sarcolemma (white arrows) with FITC-conjugated lectin. (B) Capillary locations were digitized (green circles), and the area of tissue supplied by each capillary was calculated by Voronoi tessellation (black lines). (C) Capillary density was reduced in MCT and less so in MCT+BB compared to CON. (D) There were no differences between groups in the ratio of capillaries to muscle fibers. (E) The capillary supply area was greater in MCT and MCT $+\mathrm{BB}$ than CON, but was reduced in MCT + BB compared to MCT. $n=6$ hearts per group. ${ }^{*} p<0.05,{ }^{* *} p<0.01$, *** $p<0.001$.

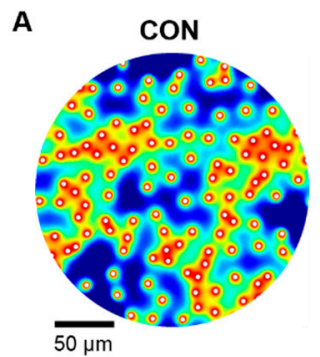

B

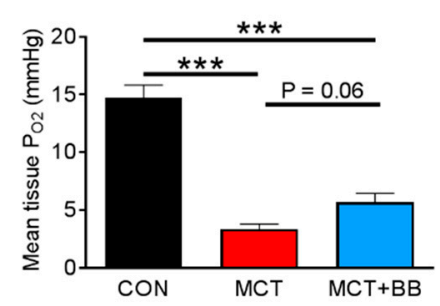

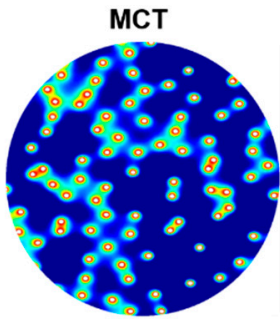

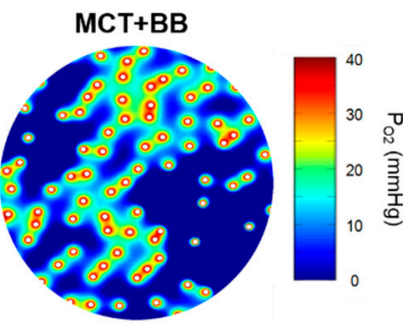

C

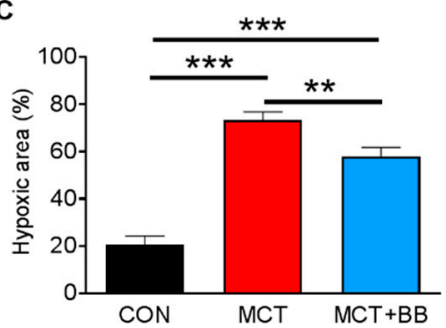

Figure 2. Computer modelling predicts RV hypoxia in pulmonary arterial hypertension (PAH) is ameliorated by beta-1 blocker (BB) treatment. (A) Example heat maps showing areas of high $\mathrm{P}_{\mathrm{O} 2}$ surrounding capillary locations (white circles) and hypoxic regions distal to the capillaries. (B) Mean tissue $\mathrm{P}_{\mathrm{O} 2}$ was reduced in $\mathrm{MCT}$ and $\mathrm{MCT}+\mathrm{BB}$ compared to $\mathrm{CON}$. (C) The hypoxic area was greater in MCT than CON, but was reduced in MCT+BB compared to MCT. ${ }^{* *} p<0.01,{ }^{* * *} p<0.001 . n=6$ rats per group. 
The CK system is important for distributing energy generated by mitochondria to the myofilaments, especially during hypoxia [25]. We previously reported decreased expression of CK-mt in MCT rats [29], and wanted to investigate whether this causes a functional impairment in respiration that could affect energy availability in hypoxic regions. Mitochondrial respiration was measured in permeabilized isolated RV cardiomyocytes in response to increasing concentrations of ADP [27,47]. The apparent $\mathrm{K}_{\mathrm{mADP}}$ in the absence of $\mathrm{Cr}$ was not different between groups $(p>0.05)$. When the experiment was repeated in the presence of $25 \mathrm{mM} \mathrm{Cr}$ (to activate CK-mt), there was a shift towards a lower $\mathrm{K}_{\mathrm{mADP}}$ in CON cells (-Cr: $0.35 \pm 0.05 \mathrm{mM} ;+\mathrm{Cr}: 0.14 \pm 0.02 \mathrm{mM} ; p<0.05)$, but no difference in MCT cells (-Cr: $0.25 \pm 0.03 \mathrm{mM}$; + Cr: $0.18 \pm 0.03 \mathrm{mM})$ or MCT + BB cells $(-C r: 0.20 \pm 0.04 \mathrm{mM} ;+$ Cr: $0.11 \pm 0.02 \mathrm{mM})$ (Figure 3A-C). The relative difference in $\mathrm{K}_{\mathrm{mADP}}$ with $\mathrm{Cr}$ in $\mathrm{CON}$ cells (61\% reduction) was greater than in MCT cells $(27 \%$ reduction) $(p<0.05)$ (Figure 3D). This indicates reduced functionality of the $\mathrm{CK}$ system to activate respiration in MCT cells. The difference in $\mathrm{K}_{\mathrm{mADP}}$ in MCT+BB in the presence of $\mathrm{Cr}(42 \%)$ was not different to CON or MCT $(p>0.05)$, suggesting CK-mt function in MCT+BB is intermediate between groups.
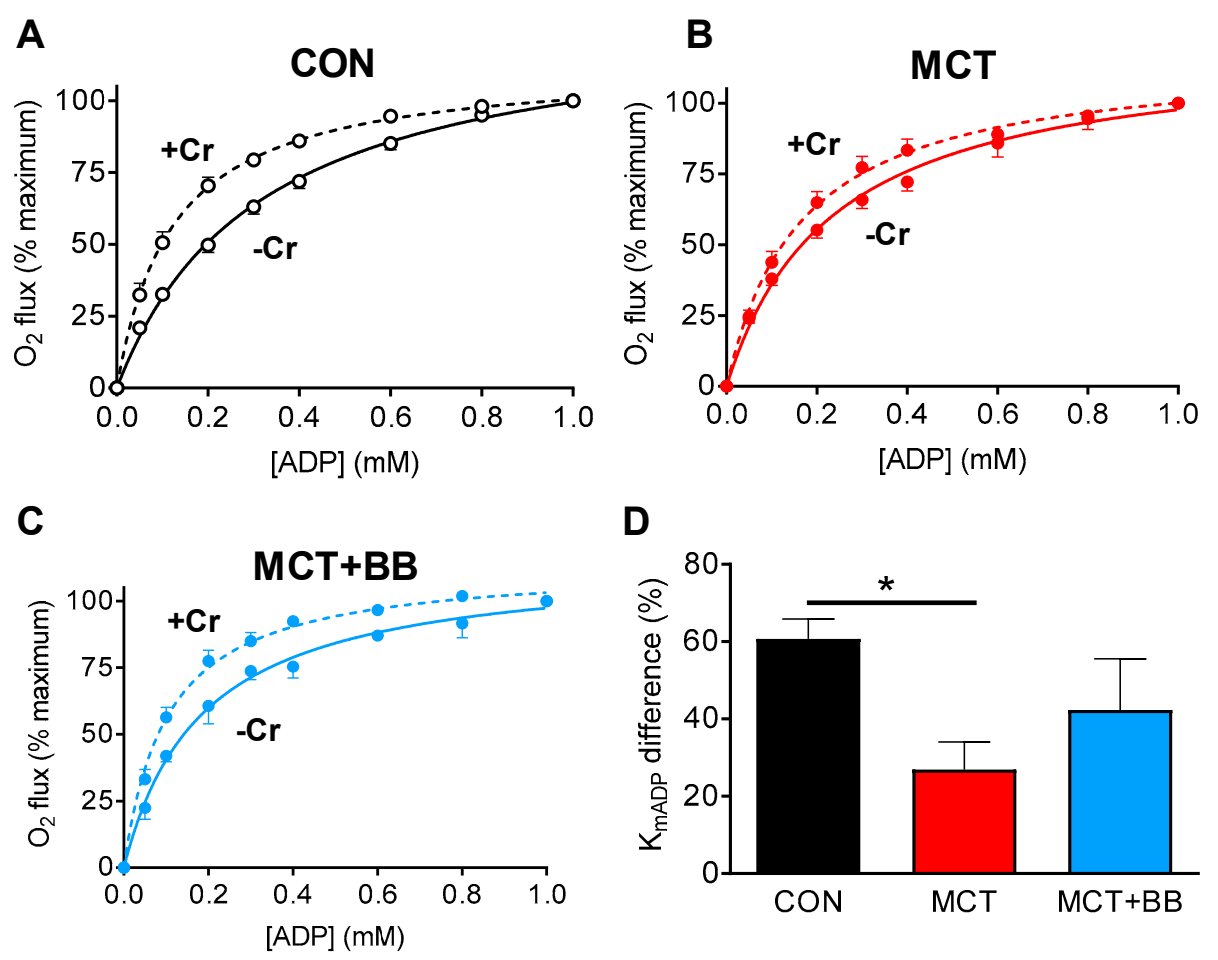

Figure 3. Coupling of mitochondrial respiration to the creatine kinase (CK) system is decreased in MCT. (A-C) The increase in $\mathrm{O}_{2}$ consumption of permeabilized RV myocytes upon sequential titration of ADP was measured in the absence (solid line) or presence (dashed line) of Cr. (D) The relative difference in $\mathrm{K}_{\mathrm{mADP}}$ with $\mathrm{Cr}$ compared to without $\mathrm{Cr}$ was greater in $\mathrm{CON}$ than $\mathrm{MCT}$, but not greater than in $\mathrm{MCT}+\mathrm{BB} .{ }^{*} p<0.05 . n=8 \mathrm{CON}, 5 \mathrm{MCT}, 3 \mathrm{MCT}+\mathrm{BB}$ independent replicates.

\section{Discussion}

We demonstrate that a reduction in capillary density is predicted to result in severe myocardial hypoxia in the failing RV in PAH. Chronic BB administration reduces RV hypertrophy in PAH [34,37], and we now show that it also ameliorated the extent of hypoxia in BB-treated rats. We also show CK-mt function is impaired in MCT RV cells. This may alter the balance of high-energy phosphates within the cell and reduce the rate of energy turnover at ATPases. The changes seen are likely to reduce RV contractile performance in PAH, particularly during increased demand [29]. These data suggest that a beta-adrenoceptor blockade is a viable strategy to sustain the contractility of the RV in PAH, by improving the metabolic state of the myocardium. 
The schema presented in Figure 4 highlights the changes we observed in PAH and some functional implications. Increased maximum diffusion distance between capillaries and muscle fibers resulted in a proliferation of hypoxic regions. This would impair mitochondrial ATP generation in these regions and could be driving increased expression of hypoxia-related genes and increased glycolysis [17,18]. At the subcellular level, reduced activity of CK isoforms decreases high energy phosphate transfer between mitochondria and myofibrils in the hypoxic regions. This reduces the rate of ATP turnover at sites such as the myofibrils and SERCA, thus impairing contraction and preventing them contributing to cardiac work.

\section{CON}

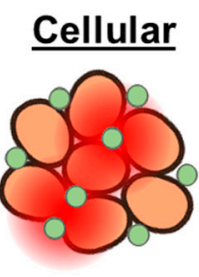

Subcellular

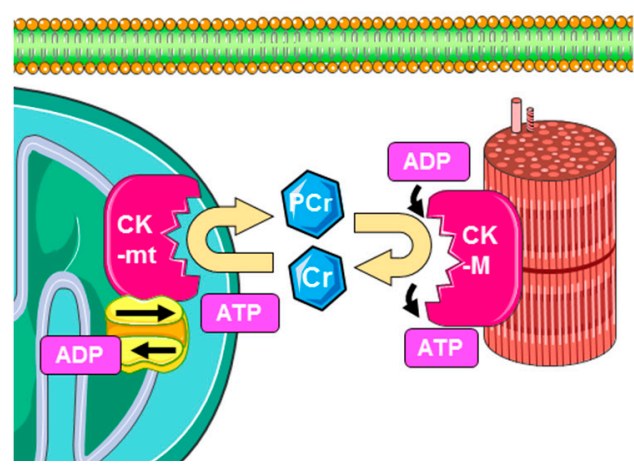

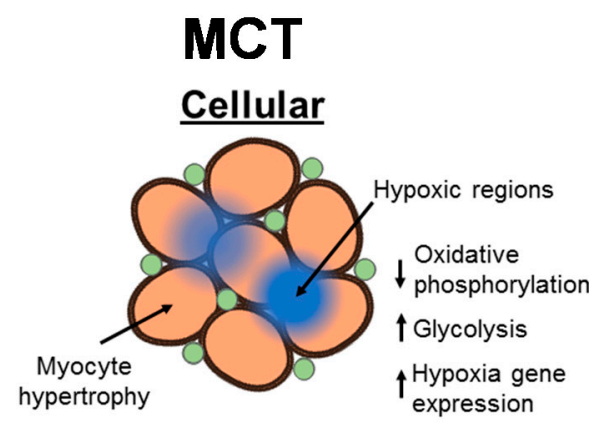

Subcellular

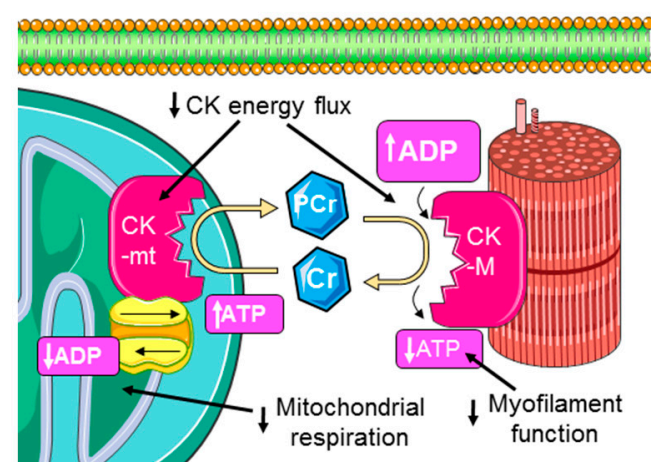

Figure 4. Cartoon representation of proposed changes in structure and function of RV myocytes in PAH. In CON cells (left), the densely packed capillary network delivers $\mathrm{O}_{2}$ evenly throughout the myocardium, maintaining a high $\mathrm{P}_{\mathrm{O} 2}$ (red regions). Mitochondria utilize $\mathrm{O}_{2}$ for oxidative phosphorylation, generating ATP. Mitochondrial-bound CK (CK-mt) use ATP to generate PCr, which diffuses to cytosolic sites of high ATP turnover, such as myofilaments, where cytosolic CK converts it back to ATP. This maintains a high ATP:ADP ratio in the myofilaments, allowing them to work properly, and a low ATP:ADP ratio in mitochondria, promoting ATP synthesis. In MCT cells (right), RV myocyte hypertrophy increases the diffusion distance of $\mathrm{O}_{2}$ from the capillaries, resulting in hypoxic cores developing within muscle fibres (blue regions). These areas are unable to meet metabolic needs entirely aerobically, so they become reliant on glycolysis. Energy transport to hypoxic cores is further impaired by reduced expression of CK isoforms, resulting in accumulation of ADP in myofilaments and reduced mitochondrial respiration. Cartoon was created using Servier Medical Art by Servier, which is licensed under a Creative Commons Attribution 3.0 Unported License (http://www.servier.com/slidekit)

\subsection{Insufficient Capillary Supply Produces Extensive Myocardial Hypoxia in Monocrotaline Rats}

Hypertrophy of the RV was apparent in MCT rats, but was reduced following BB treatment (Table 1). The increase in RV myocyte hypertrophy without an increase in the capillary:fiber ratio increased the mean area of myocardium supplied by each capillary, leading to hypoxia. Hypoxia triggers changes in the transcription factors regulating angiogenesis, which follow a complex expression pattern possibly related to disease severity and temporal state $[12,34,48]$. Decreased proangiogenic micro-RNAs and increased expression of inhibitors of VEGF and angiopoetin-1 have also been reported to increase in latter stage heart failure, which could explain the lack of angiogenesis $[13,21,22]$. 
A steep $\mathrm{O}_{2}$ gradient between the cell periphery and core of cardiac myocytes is expected to exist, due to densely packed subsarcolemmal mitochondria [49]. This gradient should be more apparent in a hypertrophic myocardium with greater $\mathrm{O}_{2}$ diffusion distances. By applying a computer model of $\mathrm{O}_{2}$ flux in the myocardium to our experimental findings in heart failure, we were able to quantify the effect of capillary density reduction on myocardial hypoxia. The three-fold increase in the hypoxic area in MCT rats implies an increase in tissue fraction, which is unable to contribute substantially to ventricular work. These areas will not necessarily become necrotic, as non-contracting myocytes with low $\mathrm{O}_{2}$ demand could be sustained through anaerobic glycolytic pathways [25]. BB reduced the proportion of hypoxic tissue, mainly by limiting myocyte hypertrophy (Figure 1E and Table 1). BB may have further benefits in vivo by reducing heart rate, and therefore $\mathrm{O}_{2}$ demand, and increasing diastolic coronary perfusion $[5,19]$.

Coronary artery disease is increasingly prevalent in PAH patients [50], and occurs around four times more frequently among that group than in the general population [51,52]. Coronary artery remodeling also occurs in parallel with the development of MCT-induced PAH, and is associated with reduced coronary perfusion [53]. Modulation of transcription factor activity by scaffold proteins, e.g., bromodomain protein 4 (BRD4), is implicated in coronary artery disease by altering the balance of proliferation and apoptosis of smooth muscle cells [53]. Decreased RV coronary perfusion is likely to exacerbate the microcirculatory impairment we identify. BB may protect against the ischemic consequences of coronary artery disease in the RV, as in the LV [54].

Our observations suggest that normalizing the capillary supply area in PAH would be beneficial. One way to achieve this would be augmenting angiogenesis. Exercise improves cardiac function [55], and increases angiogenesis and oxygen uptake efficiency [56]. Exercise therapy now has cautious recommendation in PAH guidelines [9]. We have shown that exercise has a beneficial effect in the MCT rat model [57].

\subsection{Reduced Mitochondrial Synthesis of Phosphocreatine in Monocrotaline Rats}

The CK system has a vital role maintaining a high [ADP] in mitochondria and a low [ADP] at the myofibrils. The less negatively charged and smaller molecular weight phosphocreatine (PCr) has greater cytosolic mobility than adenine nucleotides [58,59], so it acts as a shuttle of high energy phosphates to sites of high ATP turnover, such as the myofilaments. This also allows sudden changes in cellular energy demand to feed back to mitochondria, which sense an increase in cellular [ADP] and increase ATP production accordingly, e.g., during periods of increased heart rate. We identified uncoupling of the CK system with mitochondrial respiration, which was likely due to decreased expression of CK-mt [29]. This may limit the ability of mitochondria to respond rapidly to a sudden increase in work, as was demonstrated in MCT RV trabeculae [60]. A small decrease in $\mathrm{Cr}$ and $\mathrm{PCr}$ levels, which could further decrease CK flux in vivo, has been reported in the MCT model as well as other animal heart failure models and human heart failure [61-63]. The mechanical efficiency of the failing RV is also reduced, which will further increase the magnitude of the energy demand mismatch [64,65].

\subsection{Limitations}

Different classes of BB may have distinct effects in PAH. Carvedilol has mixed alpha and beta-1/2 adrenoceptor blocking ability, and nebivolol has pulmonary vasodilatory ability. Both were found to reduce afterload and adverse remodeling in experimental PAH [34,36]. Metoprolol is a beta-1 selective blocker, and is therefore predicted to be more specific to the myocardium rather than vasculature. We chose metoprolol to investigate the direct actions of a beta-blockade on the myocardium without confounding effects due to afterload reduction [35]. The response to BB may also depend on the etiology of PAH. BB are currently not recommended in Group 1 pulmonary hypertension (PAH), whereas BB are more likely to be prescribed in Group 2 pulmonary hypertension (secondary to LV failure), due to co-morbidities. MCT is known to affect the lungs, liver, and kidneys [66]. Increased wet 
lung weight is indicative of pulmonary edema; however, proliferation of lung tissue will also increase the dry lung weight [67].

\subsection{Conclusion}

We demonstrate that $\mathrm{BB}$ treatment reduced hypertrophy in experimental $\mathrm{PAH}$, resulting in a reduction in hypoxic myocardium. This was accompanied by a partial improvement in functional coupling between mitochondria and the CK energy system. These improvements are likely to act in concert to favorably affect energy availability in RV myocytes, which will help maintain cardiac function for longer. These data add to previous findings of improvements in excitation-contraction coupling, electrical remodeling, and inflammation following BB in experimental PAH $[34,35,37]$. BB were well tolerated in Group 1 PAH patients under close clinical supervision, and showed preserved cardiac function and reduced RV glycolysis after six months of treatment [33]. Together with our preclinical findings, this supports the notion that BBs may be beneficial in PAH by reducing adverse cardiac remodeling, although further testing in both preclinical and carefully controlled clinical settings will be required to confirm this.

\section{Materials and Methods}

All experiments were conducted in accordance with the Animals (Scientific Procedures) Act (1986), the European Parliament Directive 2010/63/EU, and with local ethical approval (70/8399, 14 February 2015).

We used the well-characterized monocrotaline (MCT) rat model of PAH, described in detail in [37]. Briefly, a single intraperitoneal injection of MCT $(60 \mathrm{mg} / \mathrm{kg})$ into male Wistar rats $(200 \pm 20 \mathrm{~g})$ causes a progressive increase in pulmonary vascular resistance and RV systolic pressure, eventually leading to RV failure. The beta-1 adrenergic receptor blocker metoprolol $(10 \mathrm{mg} / \mathrm{kg})$ was administered daily by voluntary syringe feeding, starting on day 15 post-MCT injection, as described previously [37,38]. MCT animals were killed upon showing signs of heart failure, such as weight loss on consecutive days, dyspnea, and piloerection. These symptoms have been validated as indicative of RV failure in this model [68-72].

\subsection{Histology}

Tissue was prepared for histology, as described in [37]. Tissue sections $10 \mu \mathrm{m}$ thick were plated on microscope slides and fixed in acetone for $5 \mathrm{~min}$ on ice. Slides were incubated for $1 \mathrm{~h}$ with fluorescein-conjugated lectin from Griffonia simplicifolia (Vector Laboratories, Burlingame, CA, USA), at a final concentration of $10 \mu \mathrm{g} / \mathrm{mL}$ in phosphate-buffered saline. Slides were imaged on a Nikon Eclipse E600 microscope with a Nikon Plan Fluor 20X objective, using $487 \pm 10 \mathrm{~nm}$ excitation light and fluorescence collected at $533 \pm 20 \mathrm{~nm}$. Capillaries were identified by the bright focal staining pattern and their location digitized. Muscle fiber boundaries were identified by the less intense staining of the glycocalyx surrounding the cell membrane. Fibrosis was assessed using picrosirius red staining, as described previously [29]. Results from two to five sections per heart were averaged to calculate the representative value for each animal, which was used for subsequent statistical analysis.

\subsection{Computer Modelling $\mathrm{O}_{2}$ Distribution}

We used a finite element model of $\mathrm{O}_{2}$ diffusion implemented in Matlab and described in detail in [39-41]. Model parameters used were in accordance with published literature [73], and were kept constant for all groups.

\subsection{Mitochondrial Respiration in Isolated Myocytes}

Single RV myocytes were isolated by enzymatic digestion of the heart on a Langendorff apparatus, as previously described [74]. Cells were resuspended in a respiration recording solution containing the 
following (in mM): 110 sucrose, $60 \mathrm{~K}$-lactobionate, 20 HEPES, 20 taurine, 10 glutamate, $10 \mathrm{KH}_{2} \mathrm{PO}_{4}$, $3 \mathrm{MgCl}_{2}, 0.5$ malate, $0.5 \mathrm{EGTA}, 1 \mathrm{mg} / \mathrm{mL}$ bovine serum albumin ( $\mathrm{pH} 7.1$ with $\mathrm{KOH}$ ). Equal volumes of cell suspension were added to both chambers of an Oxygraph-2k (Oroboros Instruments, Inssbruck, Austria). In one chamber, $25 \mathrm{mM}$ creatine was added to the media. The sarcolemma was selectively permeabilized with $50 \mu \mathrm{g} / \mathrm{mL}$ saponin injected directly into the chamber using a Hamilton syringe. $\mathrm{O}_{2}$ flux was recorded in response to sequential titrations of ADP [27,47]. Temperature was maintained at $37^{\circ} \mathrm{C}$, and $\mathrm{O}_{2}$ concentration was maintained between 200 and $400 \mu \mathrm{M}$ throughout the experiment. Data were normalized to $\mathrm{O}_{2}$ flux in the absence of ADP $(0 \%)$ and at the maximal flux in $1 \mathrm{mM}$ ADP $(100 \%)$. The apparent affinity for ADP $\left(\mathrm{K}_{\mathrm{mADP}}\right)$ was determined by fitting Michaelis-Menten kinetics to the normalized data.

\subsection{Enzyme Activity Assays}

RV samples were homogenized on ice in a buffer containing, in mM, 5 HEPES, 1 EDTA, $5 \mathrm{MgCl}_{2}$, and $0.1 \%$ Triton-X100 [75]. Protease inhibitors (cOmplete Protease Inhibitor Cocktail, Roche, Bazel, Switzerland) and phosphatase inhibitors (Halt Phosphatase Inhibitor Cocktail, Thermo Scientific, Waltham, MA, USA) were added to the buffer immediately before use. CK activity in samples was measured spectrophotometrically from the production of NADPH, according to the Rosalki assay [76], with absorption measured at $340 \mathrm{~nm}$. Next, $\beta$-mercaptoethanol $(1 \mathrm{mM})$ was added prior to the CK activity assay, to prevent the oxidation of CK. Citrate synthase activity was measured using a spectrophotometer (Varioscan Flash, Thermo Scientific, Waltham, MA, USA) according to the enzyme assay described by Srere [77]. Enzyme activity was expressed in international units per mg protein (IU/mg).

\subsection{Statistics}

Data are presented as mean \pm standard error of mean (SEM). Parametric ANOVA was performed on normally distributed data-otherwise, non-parametric equivalents were used. Holm-Sidak post hoc tests used were for parametric ANOVA, or Dunn's (unequal group sizes) for non-parametric ANOVA. The number of independent replicates (hearts or cell isolations) are given in figure legends, and $p<0.05$ was considered statistically significant.

Author Contributions: Conceptualization: E.D.F. and E.W.; data curation: E.D.F.; formal analysis: E.D.F.; funding acquisition: D.S.S. and E.W.; investigation: E.D.F.; methodology: E.D.F., D.H., J.B., and S.E.; project administration: E.W.; resources: D.H., J.B., S.E., and E.W.; software: S.E.; supervision: D.S.S. and E.W.; validation, E.D.F; visualization: E.D.F.; writing - original draft: E.D.F.; writing - review and editing: E.D.F., D.H., J.B., S.E., D.S.S., and E.W.

Funding: This work was supported by a British Heart Foundation grant [PG/13/3/29924].

Acknowledgments: We gratefully acknowledge the contribution of Roger Kissane in the application of the oxygen modelling software.

Conflicts of Interest: The authors declare no conflict of interest.

\section{Abbreviations}

$\begin{array}{ll}\text { BB } & \text { beta-adrenergic receptor blocker } \\ \text { CK } & \text { creatine kinase } \\ \text { CON } & \text { saline-injected control } \\ \text { Cr } & \text { creatine } \\ \text { MCT } & \text { monocrotaline } \\ \text { MCT+BB } & \text { monocrotaline + beta blocker } \\ \text { PCr } & \text { phosphocreatine } \\ \text { SERCA } & \text { sarco(endo)plasmic reticulum } \mathrm{Ca}^{2+} \text { ATPase }\end{array}$




\section{References}

1. Haddad, F.; Doyle, R.; Murphy, D.J.; Hunt, S.A. Right Ventricular Function in Cardiovascular Disease, Part II: Pathophysiology, Clinical Importance, and Management of Right Ventricular Failure. Circulation 2008, 117, 1717-1731. [CrossRef]

2. Humbert, M.; Guignabert, C.; Bonnet, S.; Dorfmuller, P.; Klinger, J.R.; Nicolls, M.R.; Olschewski, A.J.; Pullamsetti, S.S.; Schermuly, R.T.; Stenmark, K.R.; et al. Pathology and pathobiology of pulmonary hypertension: State of the art and research perspectives. Eur. Respir. J. 2019, 53, 1801887. [CrossRef] [PubMed]

3. Vonk Noordegraaf, A.; Westerhof, B.E.; Westerhof, N. The Relationship Between the Right Ventricle and its Load in Pulmonary Hypertension. J. Am. Coll. Cardiol. 2017, 69, 236-243. [CrossRef]

4. Henkens, I.R.; Van Wolferen, S.A.; Gan, C.T.-J.; Boonstra, A.; Swenne, C.A.; Twisk, J.W.; Kamp, O.; van der Wall, E.E.; Schalij, M.J.; Vonk-Noordegraaf, A.; et al. Relation of Resting Heart Rate to Prognosis in Patients with Idiopathic Pulmonary Arterial Hypertension. Am. J. Cardiol. 2009, 103, 1451-1456. [CrossRef]

5. Wong, Y.Y.; Westerhof, N.; Ruiter, G.; Lubberink, M.; Raijmakers, P.; Knaapen, P.; Marcus, J.T.; Boonstra, A.; Lammertsma, A.A.; van der Laarse, W.J.; et al. Systolic pulmonary artery pressure and heart rate are main determinants of oxygen consumption in the right ventricular myocardium of patients with idiopathic pulmonary arterial hypertension. Eur. J. Heart Fail. 2011, 13, 1290-1295. [CrossRef] [PubMed]

6. Seyfarth, T.; Gerbershagen, H.-P.; Giessler, C.; Leineweber, K.; Heinroth-Hoffmann, I.; Pönicke, K.; Brodde, O.-E. The Cardiac $\beta$-Adrenoceptor-G-protein(s)-adenylyl Cyclase System in Monocrotaline-treated Rats. J. Mol. Cell. Cardiol. 2000, 32, 2315-2326. [CrossRef] [PubMed]

7. Sun, F.; Lu, Z.; Zhang, Y.; Geng, S.; Xu, M.; Xu, L.; Huang, Y.; Zhuang, P.; Zhang, Y. Stage-dependent changes of $\beta 2$-adrenergic receptor signaling in right ventricular remodeling in monocrotaline-induced pulmonary arterial hypertension. Int. J. Mol. Med. 2018, 41, 2493-2504. [CrossRef]

8. Vescovo, G.; Jones, S.M.; Harding, S.E.; Poole-Wilson, P.A. Isoproterenol sensitivity of isolated cardiac myocytes from rats with monocrotaline-induced right-sided hypertrophy and heart failure. J. Mol. Cell. Cardiol. 1989, 21, 1047-1061. [CrossRef]

9. Galiè, N.; Humbert, M.; Vachiery, J.-L.; Gibbs, S.; Lang, I.; Torbicki, A.; Simonneau, G.; Peacock, A.; Vonk Noordegraaf, A.; Beghetti, M.; et al. 2015 ESC/ERS Guidelines for the diagnosis and treatment of pulmonary hypertension. Eur. Heart J. 2015, 37, 67-119. [CrossRef] [PubMed]

10. Ingwall, J.S.; Weiss, R.G. Is the Failing Heart Energy Starved? Circ. Res. 2004, 95, 135-145. [CrossRef]

11. Bottomley, P.A.; Panjrath, G.S.; Lai, S.; Hirsch, G.A.; Wu, K.; Najjar, S.S.; Steinberg, A.; Gerstenblith, G.; Weiss, R.G. Metabolic Rates of ATP Transfer Through Creatine Kinase (CK Flux) Predict Clinical Heart Failure Events and Death. Sci. Transl. Med. 2013, 5, 215re213. [CrossRef]

12. Redout, E.M.; Wagner, M.J.; Zuidwijk, M.J.; Boer, C.; Musters, R.J.P.; van Hardeveld, C.; Paulus, W.J.; Simonides, W.S. Right-ventricular failure is associated with increased mitochondrial complex II activity and production of reactive oxygen species. Cardiovasc. Res. 2007, 75, 770-781. [CrossRef] [PubMed]

13. Sano, M.; Minamino, T.; Toko, H.; Miyauchi, H.; Orimo, M.; Qin, Y.; Akazawa, H.; Tateno, K.; Kayama, Y.; Harada, M.; et al. p53-induced inhibition of Hif-1 causes cardiac dysfunction during pressure overload. Nature 2007, 446, 444-448. [CrossRef]

14. Sutendra, G.; Dromparis, P.; Paulin, R.; Zervopoulos, S.; Haromy, A.; Nagendran, J.; Michelakis, E. A metabolic remodeling in right ventricular hypertrophy is associated with decreased angiogenesis and a transition from a compensated to a decompensated state in pulmonary hypertension. J. Mol. Med. 2013, 91, 1315-1327. [CrossRef] [PubMed]

15. Ryan, J.J.; Archer, S.L. The Right Ventricle in Pulmonary Arterial Hypertension: Disorders of Metabolism, Angiogenesis and Adrenergic Signaling in Right Ventricular Failure. Circ. Res. 2014, 115, 176-188. [CrossRef]

16. Potus, F.; Hindmarch, C.; Dunham-Snary, K.; Stafford, J.; Archer, S. Transcriptomic Signature of Right Ventricular Failure in Experimental Pulmonary Arterial Hypertension: Deep Sequencing Demonstrates Mitochondrial, Fibrotic, Inflammatory and Angiogenic Abnormalities. Int. J. Mol. Sci. 2018, 19, 2730. [CrossRef] 
17. Oikawa, M.; Kagaya, Y.; Otani, H.; Sakuma, M.; Demachi, J.; Suzuki, J.; Takahashi, T.; Nawata, J.; Ido, T.; Watanabe, J.; et al. Increased [18F]Fluorodeoxyglucose Accumulation in Right Ventricular Free Wall in Patients With Pulmonary Hypertension and the Effect of Epoprostenol. J. Am. Coll. Cardiol. 2005, 45, 1849-1855. [CrossRef]

18. Piao, L.; Fang, Y.-H.; Cadete, V.J.; Wietholt, C.; Urboniene, D.; Toth, P.; Marsboom, G.; Zhang, H.; Haber, I.; Rehman, J.; et al. The inhibition of pyruvate dehydrogenase kinase improves impaired cardiac function and electrical remodeling in two models of right ventricular hypertrophy: Resuscitating the hibernating right ventricle. J. Mol. Med. 2010, 88, 47-60. [CrossRef] [PubMed]

19. van Wolferen, S.A.; Marcus, J.T.; Westerhof, N.; Spreeuwenberg, M.D.; Marques, K.M.J.; Bronzwaer, J.G.F.; Henkens, I.R.; Gan, C.T.-J.; Boonstra, A.; Postmus, P.E.; et al. Right coronary artery flow impairment in patients with pulmonary hypertension. Eur. Heart J. 2008, 29, 120-127. [CrossRef]

20. Anversa, P.; Ricci, R.; Olivetti, G. Effects of exercise on the capillary vasculature of the rat heart. Circulation 1987, 75, I12-I18. [PubMed]

21. Potus, F.; Ruffenach, G.; Dahou, A.; Thebault, C.; Breuils-Bonnet, S.; Tremblay, E.; Nadeau, V.; Paradis, R.; Graydon, C.; Wong, R.; et al. Downregulation of MicroRNA-126 Contributes to the Failing Right Ventricle in Pulmonary Arterial Hypertension. Circulation 2015, 132, 932-943. [CrossRef] [PubMed]

22. Drake, J.I.; Gomez-Arroyo, J.; Dumur, C.I.; Kraskauskas, D.; Natarajan, R.; Bogaard, H.J.; Fawcett, P.; Voelkel, N.F. Chronic carvedilol treatment partially reverses the right ventricular failure transcriptional profile in experimental pulmonary hypertension. Physiol. Genom. 2013, 45, 449-461. [CrossRef]

23. Kuznetsov, A.V.; Khuchua, Z.A.; Vassil'eva, E.V.; Medved'eva, N.V.; Saks, V.A. Heart mitochondrial creatine kinase revisited: The outer mitochondrial membrane is not important for coupling of phosphocreatine production to oxidative phosphorylation. Arch. Biochem. Biophys. 1989, 268, 176-190. [CrossRef]

24. Bessman, S.P.; Fonyo, A. The possible role of the mitochondrial bound creatine kinase in regulation of mitochondrial respiration. Biochem. Biophys. Res. Commun. 1966, 22, 597-602. [CrossRef]

25. Takahashi, E. Anoxic cell core can promote necrotic cell death in cardiomyocytes at physiological extracellular $\mathrm{Po}_{2}$. Am. J. Physiol.-Heart Circ. Physiol. 2008, 294, H2507-H2515. [CrossRef]

26. Ishikawa, K.; Hashimoto, H.; Mitani, S.; Toki, Y.; Okumura, K.; Ito, T. Enalapril improves heart failure induced by monocrotaline without reducing pulmonary hypertension in rats: Roles of preserved myocardial creatine kinase and lactate dehydrogenase isoenzymes. Int. J. Cardiol. 1995, 47, 225-233. [CrossRef]

27. Fowler, E.D.; Benoist, D.; Drinkhill, M.J.; Stones, R.; Helmes, M.; Wüst, R.C.I.; Stienen, G.J.M.; Steele, D.S.; White, E. Decreased creatine kinase is linked to diastolic dysfunction in rats with right heart failure induced by pulmonary artery hypertension. J. Mol. Cell. Cardiol. 2015, 86, 1-8. [CrossRef]

28. Joubert, F.; Wilding, J.R.; Fortin, D.; Domergue-Dupont, V.; Novotova, M.; Ventura-Clapier, R.; Veksler, V. Local energetic regulation of sarcoplasmic and myosin ATPase is differently impaired in rats with heart failure. J. Physiol. 2008, 586, 5181-5192. [CrossRef] [PubMed]

29. De Sousa, E.; Veksler, V.; Minajeva, A.; Kaasik, A.; Mateo, P.; Mayoux, E.; Hoerter, J.; Bigard, X.; Serrurier, B.; Ventura-Clapier, R. Subcellular Creatine Kinase Alterations. Circ. Res. 1999, 85, 68-76. [CrossRef] [PubMed]

30. So, P.P.-S.; Davies, R.A.; Chandy, G.; Stewart, D.; Beanlands, R.S.B.; Haddad, H.; Pugliese, C.; Mielniczuk, L.M. Usefulness of Beta-Blocker Therapy and Outcomes in Patients with Pulmonary Arterial Hypertension. Am. J. Cardiol. 2012, 109, 1504-1509. [CrossRef]

31. Thenappan, T.; Roy, S.S.; Duval, S.; Glassner-Kolmin, C.; Gomberg-Maitland, M. $\beta$-Blocker Therapy Is Not Associated with Adverse Outcomes in Patients With Pulmonary Arterial Hypertension: A Propensity Score Analysis. Circ. Heart Fail. 2014, 7, 903-910. [CrossRef]

32. Bandyopadhyay, D.; Bajaj, N.S.; Zein, J.; Minai, O.A.; Dweik, R.A. Outcomes of $\beta$-blocker use in pulmonary arterial hypertension: A propensity-matched analysis. Eur. Respir. J. 2015, 46, 750-760. [CrossRef]

33. Farha, S.; Saygin, D.; Park, M.M.; Cheong, H.I.; Asosingh, K.; Comhair, S.A.A.; Stephens, O.R.; Roach, E.C.; Sharp, J.; Highland, K.B.; et al. Pulmonary arterial hypertension treatment with carvedilol for heart failure: A randomized controlled trial. JCI Insight 2017, 2. [CrossRef]

34. Bogaard, H.J.; Natarajan, R.; Mizuno, S.; Abbate, A.; Chang, P.J.; Chau, V.Q.; Hoke, N.N.; Kraskauskas, D.; Kasper, M.; Salloum, F.N.; et al. Adrenergic Receptor Blockade Reverses Right Heart Remodeling and Dysfunction in Pulmonary Hypertensive Rats. Am. J. Respir. Critical Care Med. 2010, 182, 652-660. [CrossRef] 
35. de Man, F.S.; Handoko, M.L.; van Ballegoij, J.J.M.; Schalij, I.; Bogaards, S.J.P.; Postmus, P.E.; van der Velden, J.; Westerhof, N.; Paulus, W.J.; Vonk-Noordegraaf, A. Bisoprolol Delays Progression Towards Right Heart Failure in Experimental Pulmonary Hypertension. Circ. Heart Fail. 2012, 5, 97-105. [CrossRef]

36. Perros, F.; Ranchoux, B.; Izikki, M.; Bentebbal, S.; Happé, C.; Antigny, F.; Jourdon, P.; Dorfmüller, P.; Lecerf, F.; Fadel, E.; et al. Nebivolol for Improving Endothelial Dysfunction, Pulmonary Vascular Remodeling, and Right Heart Function in Pulmonary Hypertension. J. Am. Coll. Cardiol. 2015, 65, 668-680. [CrossRef]

37. Fowler, E.D.; Drinkhill, M.J.; Norman, R.; Pervolaraki, E.; Stones, R.; Steer, E.; Benoist, D.; Steele, D.S.; Calaghan, S.C.; White, E. Beta1-adrenoceptor antagonist, metoprolol attenuates cardiac myocyte Ca2+ handling dysfunction in rats with pulmonary artery hypertension. J. Mol. Cell. Cardiol. 2018, 120, 74-83. [CrossRef]

38. Fowler, E.D.; Drinkhill, M.J.; Stones, R.; White, E. Diastolic dysfunction in pulmonary artery hypertension: Creatine kinase and the potential therapeutic benefit of beta-blockers. Clin. Exp. Pharmacol. Physiol. 2018, 45, 384-389. [CrossRef]

39. Al-Shammari, A.A.; Gaffney, E.A.; Egginton, S. Re-evaluating the Use of Voronoi Tessellations in the Assessment of Oxygen Supply from Capillaries in Muscle. Bull. Math. Biol. 2012, 74, 2204-2231. [CrossRef]

40. Al-Shammari, A.A.; Gaffney, E.A.; Egginton, S. Modelling capillary oxygen supply capacity in mixed muscles: Capillary domains revisited. J. Theor. Biol. 2014, 356, 47-61. [CrossRef]

41. Al-Shammari, A.A.; Kissane, R.W.P.; Holbek, S.; Mackey, A.L.; Andersen, T.R.; Gaffney, E.A.; Kjaer, M.; Egginton, S. An integrated method for quantitative morphometry and oxygen transport modelling in striated muscle. J. Appl. Physiol. 2018, 126, 544-557. [CrossRef]

42. Goldman, D. Theoretical Models of Microvascular Oxygen Transport to Tissue. Microcirculation 2008, 15, 795-811. [CrossRef]

43. Sabbah, H.; Sharov, V.; Lesch, M.; Goldstein, S. Progression of heart failure: A role for interstitial fibrosis. Mol. Cell. Biochem. 1995, 147, 29-34. [CrossRef]

44. van der Laarse, W.J.; des Tombe, A.L.; van Beek-Harmsen, B.J.; Lee-de Groot, M.B.; Jaspers, R.T. Krogh's diffusion coefficient for oxygen in isolated Xenopus skeletal muscle fibers and rat myocardial trabeculae at maximum rates of oxygen consumption. J. Appl. Physiol. 2005, 99, 2173-2180. [CrossRef]

45. Hauton, D.; Al-Shammari, A.; Gaffney, E.A.; Egginton, S. Maternal Hypoxia Decreases Capillary Supply and Increases Metabolic Inefficiency Leading to Divergence in Myocardial Oxygen Supply and Demand. PLoS ONE 2015, 10, e0127424. [CrossRef]

46. Larsen, S.; Nielsen, J.; Hansen, C.N.; Nielsen, L.B.; Wibrand, F.; Stride, N.; Schroder, H.D.; Boushel, R.; Helge, J.W.; Dela, F.; et al. Biomarkers of mitochondrial content in skeletal muscle of healthy young human subjects. J. Physiol. 2012, 590, 3349-3360. [CrossRef]

47. Kaasik, A.; Veksler, V.; Boehm, E.; Novotova, M.; Minajeva, A.; Ventura-Clapier, R. Energetic Crosstalk Between Organelles: Architectural Integration of Energy Production and Utilization. Circ. Res. 2001, 89, 153-159. [CrossRef]

48. Partovian, C.; Adnot, S.; Eddahibi, S.; Teiger, E.; Levame, M.; Dreyfus, P.; Raffestin, B.; Frelin, C. Heart and lung VEGF mRNA expression in rats with monocrotaline- or hypoxia-induced pulmonary hypertension. Am. J. Physiol. 1998, 275, H1948-H1956. [CrossRef]

49. Palmer, J.W.; Tandler, B.; Hoppel, C.L. Biochemical properties of subsarcolemmal and interfibrillar mitochondria isolated from rat cardiac muscle. J. Biol. Chem. 1977, 252, 8731-8739.

50. Anand, V.; Roy, S.S.; Archer, S.L.; Weir, E.K.; Garg, S.K.; Duval, S.; Thenappan, T. Trends and Outcomes of Pulmonary Arterial Hypertension-Related Hospitalizations in the United States: Analysis of the Nationwide Inpatient Sample Database From 2001 Through 2012. JAMA Cardiol. 2016, 1, 1021-1029. [CrossRef]

51. Shimony, A.; Eisenberg, M.J.; Rudski, L.G.; Schlesinger, R.; Afilalo, J.; Joyal, D.; Dragatakis, L.; Hirsch, A.; Boutet, K.; Fox, B.D.; et al. Prevalence and impact of coronary artery disease in patients with pulmonary arterial hypertension. Am. J. Cardiol. 2011, 108, 460-464. [CrossRef]

52. Enbergs, A.; Burger, R.; Reinecke, H.; Borggrefe, M.; Breithardt, G.; Kerber, S. Prevalence of coronary artery disease in a general population without suspicion of coronary artery disease: Angiographic analysis of subjects aged 40 to 70 years referred for catheter ablation therapy. Eur. Heart J. 2000, 21, 45-52. [CrossRef] 
53. Meloche, J.; Lampron, M.C.; Nadeau, V.; Maltais, M.; Potus, F.; Lambert, C.; Tremblay, E.; Vitry, G.; Breuils-Bonnet, S.; Boucherat, O.; et al. Implication of Inflammation and Epigenetic Readers in Coronary Artery Remodeling in Patients with Pulmonary Arterial Hypertension. Arterioscler. Thromb. Vasc. Biol. 2017, 37, 1513-1523. [CrossRef]

54. Heidenreich, P.A.; McDonald, K.M.; Hastie, T.; Fadel, B.; Hagan, V.; Lee, B.K.; Hlatky, M.A. Meta-analysis of trials comparing beta-blockers, calcium antagonists, and nitrates for stable angina. JAMA 1999, 281, 1927-1936. [CrossRef]

55. Alleman, R.J.; Stewart, L.M.; Tsang, A.M.; Brown, D.A. Why Does Exercise “Trigger" Adaptive Protective Responses in the Heart? Dose-Response 2015, 13. [CrossRef]

56. Egginton, S. Invited review: Activity-induced angiogenesis. Pflüg. Arch.-Eur. J. Physiol. 2008, 457, 963. [CrossRef]

57. Natali, A.J.; Fowler, E.D.; Calaghan, S.; White, E. Voluntary exercise delays heart failure onset in rats with pulmonary artery hypertension. Am. J. Physiol. Heart Circ. Physiol. 2015, 309, 421-424. [CrossRef]

58. de Graaf, R.A.; van Kranenburg, A.; Nicolay, K. In vivo ${ }^{31}$ P-NMR diffusion spectroscopy of ATP and phosphocreatine in rat skeletal muscle. Biophys. J. 2000, 78, 1657-1664. [CrossRef]

59. Birkedal, R.; Laasmaa, M.; Vendelin, M. The location of energetic compartments affects energetic communication in cardiomyocytes. Front. Physiol. 2014, 5, 376. [CrossRef]

60. Wüst, R.C.I.; de Vries, H.J.; Wintjes, L.T.; Rodenburg, R.J.; Niessen, H.W.M.; Stienen, G.J.M. Mitochondrial complex I dysfunction and altered $\mathrm{NAD}(\mathrm{P}) \mathrm{H}$ kinetics in rat myocardium in cardiac right ventricular hypertrophy and failure. Cardiovasc. Res. 2016, 111, 362. [CrossRef]

61. Neubauer, S.; Horn, M.; Cramer, M.; Harre, K.; Newell, J.B.; Peters, W.; Pabst, T.; Ertl, G.; Hahn, D.; Ingwall, J.S.; et al. Myocardial Phosphocreatine-to-ATP Ratio Is a Predictor of Mortality in Patients with Dilated Cardiomyopathy. Circulation 1997, 96, 2190-2196. [CrossRef]

62. Lamberts, R.R.; Caldenhoven, E.; Lansink, M.; Witte, G.; Vaessen, R.J.; St Cyr, J.A.; Stienen, G.J.M. Preservation of diastolic function in monocrotaline-induced right ventricular hypertrophy in rats. Am. J. Physiol.-Heart Circ. Physiol. 2007, 293, H1869-H1876. [CrossRef]

63. Lygate, C.A.; Bohl, S.; ten Hove, M.; Faller, K.M.E.; Ostrowski, P.J.; Zervou, S.; Medway, D.J.; Aksentijevic, D.; Sebag-Montefiore, L.; Wallis, J.; et al. Moderate elevation of intracellular creatine by targeting the creatine transporter protects mice from acute myocardial infarction. Cardiovasc. Res. 2012, 96, 466-475. [CrossRef]

64. Wong, Y.Y.; Handoko, M.L.; Mouchaers, K.T.B.; de Man, F.S.; Vonk-Noordegraaf, A.; van der Laarse, W.J. Reduced mechanical efficiency of rat papillary muscle related to degree of hypertrophy of cardiomyocytes. Am. J. Physiol. Heart Circ. Physiol. 2010, 298, H1190-H1197. [CrossRef]

65. Pham, T.; Nisbet, L.; Taberner, A.; Loiselle, D.; Han, J.C. Pulmonary arterial hypertension reduces energy efficiency of right, but not left, rat ventricular trabeculae. J. Physiol. 2018, 596, 1153-1166. [CrossRef]

66. Roth, R.A.; Dotzlaf, L.A.; Baranyi, B.; Kuo, C.H.; Hook, J.B. Effect of monocrotaline ingestion on liver, kidney, and lung of rats. Toxicol. Appl. Pharm. 1981, 60, 193-203. [CrossRef]

67. Sugita, T.; Hyers, T.M.; Dauber, I.M.; Wagner, W.W.; McMurtry, I.F.; Reeves, J.T. Lung vessel leak precedes right ventricular hypertrophy in monocrotaline-treated rats. J. Appl. Physiol. Respir. Environ. Exerc. Physiol. 1983, 54, 371-374. [CrossRef]

68. Hardziyenka, M.; Campian, M.E.; Rianne de Bruin-Bon, H.A.C.M.; Michel, M.C.; Tan, H.L. Sequence of Echocardiographic Changes During Development of Right Ventricular Failure in Rat. J. Am. Soc. Echocardiogr. 2006, 19, 1272-1279. [CrossRef]

69. Gomez-Arroyo, J.G.; Farkas, L.; Alhussaini, A.A.; Farkas, D.; Kraskauskas, D.; Voelkel, N.F.; Bogaard, H.J. The Monocrotaline Model of Pulmonary Hypertension in Perspective. Am. J. Physiol. Lung Cell. Mol. Physiol. 2011, 302, L363-L369. [CrossRef]

70. Maarman, G.; Lecour, S.; Butrous, G.; Thienemann, F.; Sliwa, K. A comprehensive review: The evolution of animal models in pulmonary hypertension research; are we there yet? Pulm. Circ. 2013, 3, 739-756. [CrossRef]

71. Ryan, J.J.; Marsboom, G.; Archer, S.L. Rodent Models of Group 1 Pulmonary Hypertension. In Pharmacotherapy of Pulmonary Hypertension; Humbert, M., Evgenov, O.V., Stasch, J.-P., Eds.; Springer: Berlin/Heidelberg, Germany, 2013; pp. 105-149. [CrossRef] 
72. Nogueira-Ferreira, R.; Vitorino, R.; Ferreira, R.; Henriques-Coelho, T. Exploring the monocrotaline animal model for the study of pulmonary arterial hypertension: A network approach. Pulm. Pharmacol. Ther. 2015, 35, 8-16. [CrossRef]

73. Beard, D.A.; Schenkman, K.A.; Feigl, E.O. Myocardial oxygenation in isolated hearts predicted by an anatomically realistic microvascular transport model. Am. J. Physiol. Heart Circ. Physiol. 2003, 285, H1826-H1836. [CrossRef]

74. McCrossan, Z.A.; Billeter, R.; White, E. Transmural changes in size, contractile and electrical properties of SHR left ventricular myocytes during compensated hypertrophy. Cardiovasc. Res. 2004, 63, 283-292. [CrossRef]

75. Brown, R.E.; Jarvis, K.L.; Hyland, K.J. Protein measurement using bicinchoninic acid: Elimination of interfering substances. Anal. Biochem. 1989, 180, 136-139. [CrossRef]

76. Rosalki, S.B. An improved procedure for serum creatine phosphokinase determination. J. Lab. Clin. Med. 1967, 69, 696-705.

77. Srere, P.A. [1] Citrate synthase: [EC 4.1.3.7. Citrate oxaloacetate-lyase (CoA-acetylating)]. In Methods in Enzymology; John, M.L., Ed.; Academic Press: Cambridge, MA, USA, 1969; Volume 13, pp. 3-11.

(C) 2019 by the authors. Licensee MDPI, Basel, Switzerland. This article is an open access article distributed under the terms and conditions of the Creative Commons Attribution (CC BY) license (http://creativecommons.org/licenses/by/4.0/). 